\title{
VERTICAL COMPONENT \\ OF SATELLITE NAVIGATION SYSTEMS
}

\author{
Jacek Januszewski \\ Gdynia Maritime University, \\ Navigation Department \\ al. Jana Pawła II 3, 81-345 Gdynia, Poland \\ e-mail:jacekjot@am.gdynia.pl
}

\begin{abstract}
The altitude is one of four coordinates of the user's position obtained from Satellite Navigation System (SNS) measurements. The distributions (in per cent) of VDOP coefficient value for different constellations of three SNS - GPS, GLONASS and Galileo for different masking elevation angles for different user's latitudes are presented in the paper. The results of the measurements of GPS position and vertical accuracy in mode "3D" and position accuracy in mode "2D" for different GPS receivers and different receiver's antenna heights are demonstrated also. Additionally the use of vertical component of SNS in maritime navigation like the determination highly accurate sea-floor depths is presented.
\end{abstract}

Keywords: Satellite Navigation System, vertical component, VDOP coefficient, GPS vertical accuracy

\section{INTRODUCTION}

The first calculations concerning VDOP coefficient value for different GPS constellations (of 27 satellites and nominal constellation of 24 satellites) and nominal Galileo constellation (of 27 satellites) and the measurements of GPS vertical accuracy in modes 3D and 2D were realized by the author in 2005 (Januszewski 2005a, 2005b). As nowadays (September 2010) GPS system consists of 31 satellites, the number of GLONASS atellites with status operational is 20 and at the end of this year the Russian system will have Full Operational Capability (FOC) again, the Galileo system is already under construction, the additional calculations and measurements are necessary.

In the report of the U.S. Government Accountability Office (GAO) issued on May 7, 2009, we can read that there exists the very real possibility that already in 2010 the oldest GPS satellites begin to fail (GPS Health in Question, 2009). Actually 5 satellites, all block IIa, were launched in 1994 or earlier. As the nominal vitality of these satellites is 10 years only, the GPS constellation without these space vehicles must be taken in to account.

The Standard Positioning Service (SPS) uses C/A code on the L1 signal only. The SPS performance refers to the signal in space (SIS). In SPS based on a 95\% probability level and SIS only GPS system provides a global coverage predictable positioning accuracy of $9 \mathrm{~m}$ (95\%) horizontally and $15 \mathrm{~m}$ (95\%) vertically (www.navcen.uscg.gov). 


\section{VERTICAL POSITION ACCURACY}

In each Satellite Navigation System (SNS) fix position can be calculated by using the satellites with an elevation at the moment meaurements of greater than masking elevation angle $\mathrm{H}_{\min }$. There is need of at least four satellites to calculate latitude, longitude, altitude and time. The accuracy of the position solution determined by SNS is ultimately expressed as the product of a geometry factor and a pseudorange error factor (Kaplan, 2006), (HofmannWellenhof B et al., 2008):

$$
(\text { error in SNS solution })=(\text { geometry factor }) \times(\text { pseudorange error factor })
$$

As the error solution can be expressed by $\sigma_{\rho}$ - the standard deviation of the positioning accuracy, geometry factor by the dilution of precision (DOP) coefficient and pseudorange error factor by $\sigma_{\text {UERE }}$ (UERE - User Equivalent Range Error), these relation can be defined as:

$$
\sigma_{\rho}=\mathrm{DOP} \cdot \sigma_{\mathrm{UERE}}
$$

If we can obtain all four coordinates of the observer's position (latitude, longitude, altitude, time $-\varphi, \lambda, \mathrm{h}, \mathrm{t}$ ), geometry factor DOP is expressed by GDOP (Geometric Dilution of Precision), in the case of one coordinate, e.g. altitude $h$ only, geometry factor DOP is expressed by VDOP (Vertical Dilution of Precision). In this situation the vertical position accuracy at the $95 \%$ probability level $\mathrm{M}_{h}^{95 \%}$ can be approximated by:

$$
\mathrm{M}_{h}^{95 \%} \approx 2 \cdot \mathrm{VDOP} \cdot \sigma_{\mathrm{UERE}}
$$

As we know the equation giving the functional relationship between the errors in the pseudorange values and the induced errors in the computed position and time bias for the vertical dimension we can say that the $95 \%$ point for the distribution of the vertical error $\left(2 \sigma_{\mathrm{dz}}\right)$ can be estimated by the doubled product of VDOP coefficient and the user equivalent range error $\left(\sigma_{\mathrm{UERE}}\right)$.

Some years ago when VDOP $=2$ and error $\sigma_{\text {UERE }}=8 \mathrm{~m}$ (for unaided C/A code), $\mathrm{M}_{h}^{95 \%}$ was equal $32 \mathrm{~m}$. Actually we can accept that the error $\sigma_{\text {UERE }}$ is $1 \mathrm{~m}$ only (Roper E. 2010), therefore error $\mathrm{M}$ is equal $4 \mathrm{~m}$.

\section{TEST METHOD}

The GPS satellite positions were computed by using almanac data (week 556) obtained from the website: www.navcen.uscg.gov. The orbital parameters (the longitudes of the ascending node and the arguments of latitude) of all 31 GPS satellites operational in April 16, 2010 are presented in the Table 1. The values of these parameters of 27 Galileo operational satellites and 3 spare satellites are demonstrated in the Table 2. The GLONASS satellites positions were calculated by the author for the same day using the almanac obtained from the website: www.glonass-ianc.rsa.ru. The orbital parameters of these satellites are presented in the Table 3. As this system will have FOC at the end of the 2010 year the calculations were made for the nominal 24-satellites GLONASS contellation.

All calculations based on reference ellipsoid WGS-84 were computed by using author's simulating program. The interval of the latitude of the observer between $0^{\circ}$ and $90^{\circ}$ was divided into 9 zones, each $10^{\circ}$ wide. Elevation $\mathrm{H}_{\min }$ was assumed to be $5^{\mathrm{O}}, 10^{\mathrm{O}}, 15^{\mathrm{O}}, 20^{\mathrm{O}}$ and $25^{\circ}$. The calculations were not made for $\mathrm{H}_{\min }=0^{\mathrm{O}}$ because for the position fix $\mathrm{H}_{\min }$ is almost always equal at least $5^{\mathrm{O}}$. Masking angle $5^{\mathrm{O}}$ can be representative for the positioning in the open area, angle $25^{\circ}$ in restricted area. 
Table 1. GPS System - orbital parameters of 31 satellites in April 16, 2010, PRN pseudorandom noise number, $\beta$ - longitude of the ascending node, $u$ - argument of latitude

\begin{tabular}{|c|c|c|c|c|c|c|c|}
\hline \multirow{2}{*}{ Orbit } & \multirow{2}{*}{ Parametr } & \multicolumn{6}{|c|}{ Satelita/slot } \\
\hline & & 1 & 2 & 3 & 4 & 5 & 6 \\
\hline \multirow{5}{*}{ A } & PRN & 9 & 31 & 8 & 27 & - & 7 \\
\hline & input year & 1993 & 2006 & 1997 & 1992 & - & 2008 \\
\hline & block & IIa & IIR-M & IIa & IIa & - & IIR-M \\
\hline & $\beta\left[{ }^{\mathrm{O}}\right]$ & 178 & 180 & 176 & 177 & - & 180 \\
\hline & $\mathrm{u}\left[{ }^{\mathrm{O}}\right]$ & 52 & 303 & 148 & 59 & - & 181 \\
\hline \multirow{5}{*}{ B } & PRN & 16 & 1 & 28 & 12 & 30 & - \\
\hline & input year & 2003 & 2009 & 2000 & 2006 & 1996 & - \\
\hline & block & IIR & IIR-M & IIR & IIR-M & IIa & - \\
\hline & $\beta\left[{ }^{\mathrm{O}}\right]$ & 240 & - & 242 & 240 & 238 & - \\
\hline & $\mathrm{u}\left[{ }^{\mathrm{O}}\right]$ & 221 & - & 90 & 340 & 313 & - \\
\hline \multirow{5}{*}{$\mathrm{C}$} & PRN & 29 & 3 & 19 & 17 & 6 & - \\
\hline & input year & 2008 & 1996 & 2004 & 2005 & 1994 & - \\
\hline & block & IIR-M & IIa & IIR & IIR-M & IIa & - \\
\hline & $\beta\left[{ }^{\mathrm{O}}\right]$ & 302 & 293 & 304 & 301 & 297 & - \\
\hline & $\mathrm{u}\left[^{\mathrm{O}}\right]$ & 249 & 150 & 120 & 20 & 159 & - \\
\hline \multirow{5}{*}{$\mathrm{D}$} & PRN & 2 & 11 & 21 & 4 & 24 & - \\
\hline & input year & 2004 & 2000 & 2003 & 1993 & 1991 & - \\
\hline & block & IIR & IIR & IIR & IIa & IIa & - \\
\hline & $\beta\left[{ }^{\mathrm{O}}\right]$ & 359 & 347 & 1 & 0 & 3 & - \\
\hline & $\mathrm{u}\left[{ }^{\mathrm{O}}\right]$ & 271 & 32 & 170 & 309 & 159 & - \\
\hline \multirow{5}{*}{$\mathrm{E}$} & PRN & 20 & 22 & 10 & 18 & 32 & 5 \\
\hline & input year & 2000 & 2004 & 1996 & 2001 & 1990 & 2009 \\
\hline & block & IIR & IIR & IIa & IIR & IIa & IIR-M \\
\hline & $\beta\left[{ }^{\mathrm{O}}\right]$ & 58 & 61 & 61 & 61 & 65 & 60 \\
\hline & $\mathrm{u}\left[{ }^{\mathrm{O}}\right]$ & 333 & 84 & 227 & 115 & 354 & 205 \\
\hline \multirow{5}{*}{$\mathrm{F}$} & PRN & 14 & 15 & 13 & 23 & 26 & - \\
\hline & input year & 2000 & 2007 & 1998 & 2004 & 1992 & - \\
\hline & block & IIR & IIR-M & IIR & IIR & IIa & - \\
\hline & $\beta\left[{ }^{\mathrm{O}}\right]$ & 123 & 119 & 124 & 120 & 124 & - \\
\hline & $\mathrm{u}\left[{ }^{\mathrm{O}}\right]$ & 18 & 124 & 246 & 271 & 82 & - \\
\hline
\end{tabular}

For each system, for each zone of latitude and for each masking elevation angle $\left(\mathrm{H}_{\min }\right)$ one thousand (1000) geographic-time coordinates of the observer were generated by randomnumber generator with uniform distribution: 
- latitude interval $0-600$ minutes $\left(10^{\circ}\right)$,

- longitude interval $0-21600$ minutes $\left(360^{\circ}\right)$,

- time interval $0-1440$ minutes (24 hours).

For each geographic-time coordinates the number $l_{\mathrm{s}}$ of satellites visible above $\mathrm{H}_{\min }$ and VDOP coefficient value were calculated. If the number $l_{s}$ is less than 4 , the position of the user in mode " $3 \mathrm{D}$ " cannot be obtained, No Fix is greater than 0 .

VDOP value (v) was divided into 8 intervals: $1^{\text {st }}$ for $v \leq 2,2^{\text {nd }}$ for $2<v \leq 3,3^{\text {rd }}$ for $3<v \leq 4,4^{\text {th }}$ for $4<v \leq 5,5^{\text {th }}$ for $5<v \leq 6,6^{\text {th }}$ for $6<v \leq 8,7^{\text {th }}$ for $8<v \leq 20$ and $8^{\text {th }}$ for $v>20$.

Table 2. Galileo System - orbital parameters of 27 operational satellites and 3 spare satellites ${ }^{*}, \beta$ - longitude of the ascending node, $\mathrm{u}$ - argument of latitude

\begin{tabular}{|c|c|c|c|c|c|c|c|c|}
\hline \multicolumn{3}{|c|}{ Orbit I } & \multicolumn{3}{|c|}{ Orbit II } & \multicolumn{3}{|c|}{ Orbit III } \\
\hline Satellite & $\beta\left[{ }^{\mathrm{O}}\right]$ & $\mathrm{u}\left[{ }^{\mathrm{O}}\right]$ & Satellite & $\beta\left[{ }^{\mathrm{O}}\right]$ & $\mathrm{u}\left[{ }^{\mathrm{O}}\right]$ & Satellite & $\beta\left[{ }^{\mathrm{O}}\right]$ & $\mathrm{u}\left[{ }^{\mathrm{O}}\right]$ \\
\hline 1 & \multirow{10}{*}{296} & 0 & 10 & \multirow{10}{*}{176} & 14 & 19 & \multirow{10}{*}{56} & 28 \\
\hline 2 & & 40 & 11 & & 54 & 20 & & 68 \\
\hline 3 & & 80 & 12 & & 94 & 21 & & 108 \\
\hline 4 & & 120 & 13 & & 134 & 22 & & 148 \\
\hline 5 & & 160 & 14 & & 174 & 23 & & 188 \\
\hline 6 & & 200 & 15 & & 214 & 24 & & 228 \\
\hline 7 & & 240 & 16 & & 254 & 25 & & 268 \\
\hline 8 & & 280 & 17 & & 294 & 26 & & 308 \\
\hline 9 & & 320 & 18 & & 334 & 27 & & 348 \\
\hline $28^{*}$ & & 20 & $29^{*}$ & & 154 & $30 *$ & & 288 \\
\hline
\end{tabular}

Table 3. GLONASS System - orbital parameters of 24 satellites,

$\beta$ - longitude of the ascending node, $\mathrm{u}-$ argument of latitude

\begin{tabular}{|c|c|c|c|c|c|c|c|c|c|}
\hline \multirow{2}{*}{ Orbit } & \multirow{2}{*}{ Parameter } & \multicolumn{8}{|c|}{ Satellite/slot } \\
\hline & & 1 & 2 & 3 & 4 & 5 & 6 & 7 & 8 \\
\hline \multirow{3}{*}{ I } & PRN & 1 & 2 & 3 & 4 & 5 & 6 & 7 & 8 \\
\hline & $\beta\left[{ }^{o}\right]$ & 90 & 90 & 90 & 90 & 90 & 90 & 90 & 90 \\
\hline & $\mathrm{u}\left[{ }^{\mathrm{o}}\right]$ & 350 & 36 & 81 & 116 & 164 & 212 & 259 & 205 \\
\hline \multirow{3}{*}{ II } & PRN & 9 & 10 & 11 & 12 & 13 & 14 & 15 & 16 \\
\hline & $\beta\left[{ }^{o}\right]$ & 210 & 210 & 210 & 210 & 210 & 210 & 210 & 210 \\
\hline & $\mathrm{u}\left[{ }^{\mathrm{o}}\right]$ & 6 & 51 & 96 & 141 & 186 & 232 & 279 & 321 \\
\hline \multirow{3}{*}{ III } & PRN & 17 & 18 & 19 & 20 & 21 & 22 & 23 & 24 \\
\hline & $\beta\left[{ }^{\circ}\right]$ & 330 & 330 & 330 & 330 & 330 & 330 & 330 & 330 \\
\hline & $\mathrm{u}\left[{ }^{\mathrm{O}}\right]$ & 18 & 64 & 109 & 155 & 198 & 244 & 289 & 334 \\
\hline
\end{tabular}


Table 4. Distribution of VDOP coefficient value $v$ for $v \leq 2$ and $2<v \leq 3$ (in percent) for different masking elevation angles $\mathrm{H}_{\min }$, for different user's latitudes $(\varphi)$ for Galileo, GLONASS and GPS Systems with different number of satellites (NS)

\begin{tabular}{|c|c|c|c|c|c|c|c|c|c|c|c|c|}
\hline \multirow{3}{*}{$\stackrel{\varphi}{\stackrel{p}{[}]}$} & \multirow{3}{*}{ System } & \multirow{3}{*}{ NS } & \multicolumn{10}{|c|}{$\mathbf{H}_{\min }\left[{ }^{\mathrm{o}}\right]$} \\
\hline & & & \multicolumn{2}{|c|}{5} & \multicolumn{2}{|c|}{10} & \multicolumn{2}{|c|}{15} & \multicolumn{2}{|c|}{20} & \multicolumn{2}{|c|}{25} \\
\hline & & & $v \leq 2$ & $2<v \leq 3$ & $v \leq 2$ & $2<v \leq 3$ & $v \leq 2$ & $2<v \leq 3$ & $v \leq 2$ & $2<v \leq 3$ & $v \leq 2$ & $2<v \leq 3$ \\
\hline \multirow{5}{*}{ 0-10 } & \multirow{2}{*}{ GAL } & 27 & 82.6 & 17.4 & 52.5 & 47.4 & 7.1 & 87.1 & - & 70.5 & - & 34.4 \\
\hline & & 30 & 86.9 & 13.1 & 62.9 & 37.0 & 18.2 & 76.8 & 2.1 & 72.5 & 0.1 & 37.9 \\
\hline & GLO & 24 & 76.3 & 23.7 & 47.0 & 49.0 & 17.6 & 63.2 & 2.1 & 47.3 & - & 16.3 \\
\hline & \multirow{2}{*}{ GPS } & 27 & 81.7 & 17.1 & 54.3 & 39.6 & 18.7 & 60.6 & 1.8 & 51.4 & - & 25.3 \\
\hline & & 30 & 91.1 & 8.9 & 61.7 & 34.6 & 24.4 & 60.6 & 3.2 & 58.3 & - & 31.0 \\
\hline \multirow{5}{*}{ 10-20 } & \multirow{2}{*}{ GAL } & 27 & 74.5 & 25.4 & 39.5 & 58.5 & 8.4 & 77.0 & - & 55.3 & - & 26.6 \\
\hline & & 30 & 80.3 & 19.6 & 47.2 & 51.0 & 13.4 & 74.5 & 0.8 & 58.0 & 0.1 & 27.9 \\
\hline & GLO & 24 & 55.7 & 41.0 & 23.9 & 64.0 & 7.4 & 60.4 & 0.5 & 38.1 & - & 13.5 \\
\hline & \multirow{2}{*}{ GPS } & 27 & 75.6 & 21.4 & 41.3 & 47.6 & 12.4 & 60.9 & 1.5 & 45.1 & 0.1 & 15.3 \\
\hline & & 30 & 80.6 & 17.0 & 47.1 & 44.9 & 15.8 & 64.1 & 2.4 & 52.3 & 0.2 & 20.0 \\
\hline \multirow{5}{*}{ 20-30 } & \multirow{2}{*}{ GAL } & 27 & 73.5 & 222.6 & 445.1 & 48.2 & 12.9 & 74.1 & - & 56.9 & 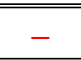 & 25.3 \\
\hline & & 30 & 77.6 & 19.3 & 49.2 & 45.8 & 14.0 & 75.5 & - & 60.4 & - & 27.9 \\
\hline & GLO & 24 & 34.3 & 63.7 & 11.2 & 75.3 & 2.0 & 65.9 & 0.1 & 40.6 & - & 19.1 \\
\hline & \multirow{2}{*}{ GPS } & 27 & 72.5 & 24.6 & 38.7 & 48.7 & 12.9 & 54.2 & 1.0 & 38.4 & - & 16.0 \\
\hline & & 30 & 79.4 & 18.2 & 47.8 & 43.0 & 17.4 & 57.3 & 2.1 & 45.6 & - & 20.9 \\
\hline \multirow{5}{*}{$30-40$} & \multirow{2}{*}{ GAL } & 27 & $\begin{array}{l}90.1 \\
\end{array}$ & 9.2 & $\begin{array}{l}63.8 \\
\end{array}$ & 31.0 & $\begin{array}{l}17.9 \\
\end{array}$ & $\begin{array}{l}70.3 \\
\end{array}$ & - & 63.3 & - & $\begin{array}{l}17.7 \\
\end{array}$ \\
\hline & & 30 & 92.6 & 6.8 & 67.0 & 28.8 & 19.2 & 71.6 & - & 67.7 & - & 20.0 \\
\hline & GLO & 24 & 33.6 & 64.4 & 6.0 & 84.6 & 0.4 & 71.3 & 0.1 & $\begin{array}{l}49.7 \\
\end{array}$ & 0.1 & 25.7 \\
\hline & \multirow{2}{*}{ GPS } & 27 & 70.4 & 26.7 & 38.7 & 48.7 & 12.9 & 54.2 & 1.0 & 38.4 & - & 19.7 \\
\hline & & 30 & 78.9 & 19.4 & 49.8 & 42.0 & 20.4 & 56.3 & 4.3 & 48.1 & - & 25.7 \\
\hline & & 27 & 85.1 & $\begin{array}{l}11.6 \\
\end{array}$ & 55.6 & 36.6 & $\begin{array}{l}19.3 \\
\end{array}$ & 69.2 & 0.6 & $\begin{array}{l}70.9 \\
\end{array}$ & - & 39.3 \\
\hline & GAL & 30 & 88.9 & 9.7 & 61.8 & 34.0 & 24.3 & 67.9 & 1.4 & 74.6 & - & 44.3 \\
\hline $40-50$ & GLO & 24 & 73.3 & 25.2 & 26.8 & 65.9 & 2.6 & 75.5 & 0.3 & 52.3 & 0.1 & 27.8 \\
\hline & CPS & 27 & 73.0 & 23.4 & 47.8 & 41.9 & 18.7 & 55.0 & 2.4 & 48.6 & 0.1 & 23.8 \\
\hline & GPS & 30 & 82.4 & 16.2 & 57.5 & 36.2 & 24.4 & 57.2 & 4.0 & 55.1 & 0.2 & 29.8 \\
\hline & GAI & 27 & 92.9 & 6.5 & 71.1 & 24.6 & 25.6 & 63.7 & 2.8 & 711.4 & - & 45.9 \\
\hline & GAL & 30 & 95.1 & 4.7 & 76.7 & 20.5 & 31.1 & 61.7 & 4.5 & 73.7 & 0.1 & 50.5 \\
\hline $50-60$ & GLO & 24 & 85.8 & 14.2 & 59.9 & 39.9 & 23.1 & 71.3 & 1.5 & 73.7 & - & 42.4 \\
\hline & CPS & 27 & 79.5 & 18.4 & 52.4 & 39.3 & 19.4 & 56.1 & 2.7 & 46.6 & 0.2 & 24.2 \\
\hline & GPS & 30 & 87.3 & 12.3 & 61.8 & 35.2 & 24.4 & 59.2 & 3.8 & 55.1 & 0.2 & 30.5 \\
\hline & GAI & 27 & 92.9 & 7.1 & 68.3 & 31.6 & 25.7 & 70.6 & 1.8 & 76.5 & - & 34.3 \\
\hline & GAL & 30 & 95.7 & 4.3 & 74.1 & 25.9 & 31.1 & 66.4 & 2.6 & 78.9 & - & 38.9 \\
\hline $60-70$ & GLO & 24 & 73.7 & 26.3 & 51.6 & 47.6 & 26.6 & 61.7 & 6.7 & 61.5 & 0.1 & 42.8 \\
\hline & & 27 & 65.2 & 30.9 & 39.6 & 48.1 & 14.2 & 55.0 & 1.1 & $\begin{array}{l}44.1 \\
\end{array}$ & - & 19.6 \\
\hline & GPS & 30 & 72.1 & 28.9 & 47.1 & 45.4 & 17.9 & 59.5 & 1.9 & 50.6 & - & 24.8 \\
\hline & GAL & 27 & 54.3 & 45.7 & 13.1 & 86.5 & 0.4 & 93.0 & - & 61.4 & $\begin{array}{l}- \\
\end{array}$ & 21.3 \\
\hline & GAL & 30 & 65.4 & 34.6 & 26.1 & 73.7 & 4.0 & 91.3 & - & 65.0 & - & 22.2 \\
\hline $70-80$ & GLO & 24 & 72.3 & 27.7 & 35.4 & 62.5 & 8.0 & 77.4 & 0.3 & 58.9 & - & 30.2 \\
\hline & $G$ & 27 & 444.1 & 47.5 & 15.3 & 62.6 & 3.0 & $\begin{array}{l}51.2 \\
\end{array}$ & 0.1 & 27.9 & - & 7.0 \\
\hline & GPS & 30 & 49.3 & 48.6 & 19.6 & 63.8 & 3.8 & 56.0 & 0.1 & 32.6 & - & 8.6 \\
\hline
\end{tabular}


Table 4. cont.

\begin{tabular}{||c|c|c||c|c|c|c|c|c|c|c|c|c||}
\hline \multirow{4}{*}{$80-90$} & \multirow{2}{*}{ GAL } & 27 & 33.4 & 66.5 & 4.1 & 93.4 & - & 63.0 & - & 14.6 & - & 0.4 \\
\cline { 2 - 14 } & & 30 & 47.2 & 52.8 & 10.0 & 88.8 & - & 69.3 & - & 17.5 & - & 0.4 \\
\cline { 2 - 14 } & \multirow{2}{*}{ GPS } & 24 & 70.6 & 29.4 & 24.7 & 73.8 & 3.4 & 89.5 & - & 70.1 & - & 22.6 \\
\cline { 3 - 14 } & & 27 & 33.8 & 55.4 & 3.0 & 69.1 & - & 36.8 & - & 5.1 & - & - \\
\hline
\end{tabular}

Table 5. Distribution of VDOP coefficient value $v$ and without fix (in percent) for different masking elevation angles $\mathrm{H}_{\min }$, for Galileo, GLONASS and GPS Systems with different number of satellites (NS) at latitude $50-60^{\circ}$

\begin{tabular}{|c|c|c|c|c|c|c|c|c|c|c|c|}
\hline \multirow{2}{*}{$\underset{\left[{ }^{\mathrm{O}}\right]}{\mathbf{H}_{\min }}$} & \multirow{2}{*}{ System } & \multirow{2}{*}{ NS } & \multirow{2}{*}{$\begin{array}{c}\text { With- } \\
\text { out Fix } \\
{[\%]}\end{array}$} & \multicolumn{8}{|c|}{ VDOP coefficient value $-v[\%]$} \\
\hline & & & & $v \leq 2$ & $\mathbf{2}<\mathbf{v} \leq \mathbf{3}$ & $3<v \leq 4$ & $4<v \leq 5$ & $5<v \leq 6$ & $6<v \leq 8$ & $8<v \leq \mathbf{2 0}$ & $\mathbf{v}>\mathbf{2 0}$ \\
\hline \multirow{5}{*}{5} & \multirow{2}{*}{ GAL } & 27 & - & 92.9 & 6.5 & 0.6 & - & - & - & - & - \\
\hline & & 30 & - & 95.1 & 4.7 & 0.2 & - & - & - & - & - \\
\hline & GLO & 24 & - & 85.8 & 14.2 & - & - & - & - & - & - \\
\hline & \multirow{2}{*}{ GPS } & 27 & - & 79.5 & 18.4 & 1.8 & 0.3 & - & - & - & - \\
\hline & & 30 & - & 87.3 & 12.3 & 0.4 & - & - & - & - & - \\
\hline \multirow{5}{*}{10} & \multirow{2}{*}{ GAL } & 27 & 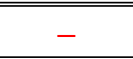 & 71.1 & 24.6 & $\begin{array}{l}4.3 \\
\end{array}$ & - & - & - & - & - \\
\hline & & 30 & - & 76.7 & 20.5 & 2.8 & - & - & - & - & - \\
\hline & GLO & 24 & - & 59.9 & 39.9 & 0.2 & - & - & - & - & - \\
\hline & \multirow{2}{*}{ GPS } & 27 & - & 52.4 & 39.3 & 6.4 & 1.3 & 0.3 & 0.1 & 0.1 & - \\
\hline & & 30 & - & 61.8 & 35.2 & 2.4 & 0.5 & - & - & 0.1 & - \\
\hline \multirow{5}{*}{15} & \multirow{2}{*}{ GAL } & 27 & - & 25.6 & $\begin{array}{l}63.7 \\
\end{array}$ & $\begin{array}{l}10.7 \\
\end{array}$ & - & - & - & ב- & - \\
\hline & & 30 & - & 31.1 & 61.7 & 7.2 & - & - & - & - & - \\
\hline & GLO & 24 & - & 23.1 & 71.3 & 4.5 & 0.3 & - & - & $\begin{array}{ll}0.1 \\
\end{array}$ & $\begin{array}{l}0.7 \\
\end{array}$ \\
\hline & \multirow{2}{*}{ GPS } & 27 & 0.3 & 19.4 & $\begin{array}{l}56.1 \\
\end{array}$ & 15.6 & 4.0 & 1.0 & 0.6 & 1.5 & 1.5 \\
\hline & & 30 & - & 24.4 & 59.2 & $\begin{array}{ll}10.8 \\
\end{array}$ & 2.5 & 1.2 & 0.4 & 1.0 & 0.5 \\
\hline \multirow{5}{*}{20} & \multirow{2}{*}{ GAL } & 27 & - & 2.8 & 71.4 & 23.7 & - & - & - & $\begin{array}{c}0.7 \\
\end{array}$ & $\begin{array}{l}1.4 \\
\end{array}$ \\
\hline & & 30 & - & 4.5 & 73.7 & 19.7 & - & - & 1.3 & 0.7 & $\begin{array}{l}0.1 \\
\end{array}$ \\
\hline & GLO & 24 & - & 1.5 & 73.7 & 15.5 & 1.2 & 0.5 & 0.5 & 0.2 & 6.9 \\
\hline & \multirow{2}{*}{ GPS } & 27 & 3.9 & 2.7 & 46.6 & 25.1 & 8.2 & 3.3 & 2.7 & 5.0 & 2.5 \\
\hline & & 30 & 1.4 & 3.8 & 55.1 & 21.2 & 8.3 & 3.0 & 2.6 & 3.6 & 1.0 \\
\hline \multirow{5}{*}{25} & \multirow{2}{*}{ GAL } & 27 & - & - & $\begin{array}{l}45.9 \\
\end{array}$ & 37.6 & 1.1 & 0.1 & 1.6 & 9.1 & 4.6 \\
\hline & & 30 & - & 0.1 & 50.5 & 33.6 & 1.1 & 1.3 & 6.3 & 5.9 & 1.2 \\
\hline & GLO & 24 & - & - & 42.4 & 24.3 & 3.6 & 2.5 & 2.7 & 3.7 & 20.8 \\
\hline & \multirow{2}{*}{ GPS } & 27 & 13.7 & 0.2 & 24.2 & 27.0 & 11.6 & 5.0 & 6.4 & 8.1 & 3.8 \\
\hline & & 30 & 5.9 & 0.2 & 30.5 & 27.5 & 13.9 & 5.2 & 7.1 & 7.1 & 2.6 \\
\hline
\end{tabular}

In the case of the GPS system the calculations were made for the constellation of 30 satellites without the oldest satellite, $\mathrm{PRN}=32$, launched in 1990 year (20 years ago) and the constellation of 27 satellites (without three the oldest satellites 9, 26 and 27 additionally). It was assumed that the GLONASS system is fully operational with a constellation of 24 satellites.

The distributions of VDOP coefficient values $\mathrm{v}$ in 2 intervals $(\mathrm{v} \leq 2$ and $2<\mathrm{v} \leq 3)$ in per cent for two Galileo constellations, of 27 (operational only) and 30 (with spare) satellites, for 
GLONASS system constellation of 24 satellites and two GPS constellations, of 27 and 30 satellites for mentioned angles $\mathrm{H}_{\text {min }}$ for all 9 zones of user's latitudes $\varphi$ are shown in the table 4. We can say that:

Table 6. Distribution of VDOP coefficient value v (in percent) for nominal Galileo constellation of 27 satellites and GPS system constellation consisted of 27 the youngest satellites for the user at latitude $50-60^{\circ}$ for $\mathrm{H}_{\min }=5^{\mathrm{O}}$, if the number of satellites visible by this user is known

\begin{tabular}{|c|c|c|c|c|c|c|}
\hline \multirow{2}{*}{$\begin{array}{l}\text { Number of } \\
\text { satellites }\end{array}$} & \multirow{2}{*}{ System } & \multirow{2}{*}{$\%$} & \multicolumn{4}{|c|}{ VDOP coefficient value $-v[\%]$} \\
\hline & & & $v \leq 2$ & $2<v \leq 3$ & $3<v \leq 4$ & $4<v \leq 5$ \\
\hline \multirow{2}{*}{5} & GAL & - & - & - & - & - \\
\hline & GPS & 1.4 & 0.1 & 0.5 & 0.6 & 0.2 \\
\hline \multirow{2}{*}{6} & GAL & 0.6 & - & - & 0.6 & \\
\hline & GPS & 6.4 & 2.4 & 3.4 & 0.6 & - \\
\hline \multirow{2}{*}{7} & GAL & 2.3 & 0.6 & 1.7 & - & - \\
\hline & GPS & 16.4 & 10.6 & 5.2 & 0.5 & 0.1 \\
\hline \multirow{2}{*}{8} & GAL & 9.1 & 6.0 & 3.1 & - & - \\
\hline & GPS & 16.4 & 12.3 & 4.1 & - & - \\
\hline \multirow{2}{*}{9} & GAL & 22.5 & 20.9 & 1.6 & - & - \\
\hline & GPS & 15.9 & 13.7 & 2.1 & 0.1 & - \\
\hline \multirow{2}{*}{10} & GAL & 48.6 & 48.5 & 0.1 & - & - \\
\hline & GPS & 17.0 & 16.0 & 1.0 & - & - \\
\hline \multirow{2}{*}{11} & GAL & 16.4 & 16.4 & - & - & - \\
\hline & GPS & $\mathbf{1 4 . 4}$ & 13.5 & 0.9 & - & - \\
\hline \multirow{2}{*}{12} & GAL & 0.5 & 0.5 & - & - & - \\
\hline & GPS & 8.9 & 8.1 & 0.8 & - & - \\
\hline \multirow{2}{*}{13} & GAL & - & - & - & - & - \\
\hline & GPS & 2.9 & 2.5 & 0.4 & - & - \\
\hline \multirow{2}{*}{14} & GAL & - & - & - & - & - \\
\hline & GPS & 0.3 & 0.3 & - & - & - \\
\hline \multirow{2}{*}{ Total } & GAL & 100 & 92.9 & 6.5 & 0.6 & - \\
\hline & GPS & 100 & 79.5 & 18.4 & 1.8 & 0.3 \\
\hline
\end{tabular}

- VDOP coefficient increases with $\mathrm{H}_{\min }$ in all 9 zones for all three systems and all constellations,

- for $\mathrm{H}_{\min }=5^{\mathrm{O}}$ the probability of VDOP value less than 2 is at latitudes $0-30^{\circ}$ and 80 $90^{\circ}$ for Galileo and GPS systems and for all constellations of these systems practically the same; at latitudes $30-80^{\circ}$ this probability is greater for Galileo than for GPS system for all constellations considerably,

- for $\mathrm{H}_{\min }=25^{\mathrm{O}}$ the probability of VDOP value less than 3 is for Galileo greater than for GPS system at all latitudes, 
- for all systems for all constellations and for all $\mathrm{H}_{\min }$ angles VDOP value is less if the number of satellites is greater, at latitudes $0-70^{\circ}$ and for $\mathrm{H}_{\min }=5^{\mathrm{O}}$ this diminution is for the GPS system greater than for Galileo system considerably,

- at latitudes $0-40^{\circ}$ the probability of VDOP value less than 2 is for GLONASS system less than for Galileo and GPS considerably, at latitudes $40-60^{\circ}$ this probability is for all three systems almost the same, at latitudes $60-90^{\circ}$ this probability is for GLONASS greater than for GPS and Galileo.

Table 7. Distribution of VDOP coefficient value v (in percent) for nominal Galileo constellation of 27 operational satellites and 3 spare satellites and GPS constellation of 30 satellites for the user at latitude $50-60^{\circ}$ for $\mathrm{H}_{\min }=5^{\mathrm{O}}$,

if the number of satellites visible by this user is known

\begin{tabular}{|c|c|c|c|c|c|}
\hline \multirow{2}{*}{$\begin{array}{c}\text { Number of } \\
\text { satellites }\end{array}$} & \multirow{2}{*}{ System } & \multirow{2}{*}{$\%$} & \multicolumn{3}{|c|}{ VDOP coefficient value $-v[\%]$} \\
\hline & & & $\mathbf{v} \leq 2$ & $2<v \leq 3$ & $3<v \leq 4$ \\
\hline \multirow{2}{*}{6} & GAL & - & - & - & - \\
\hline & GPS & 1.4 & 0.2 & 1.0 & 0.2 \\
\hline \multirow{2}{*}{7} & GAL & 0.6 & - & 0.4 & 0.2 \\
\hline & GPS & 5.0 & 3.6 & 1.4 & - \\
\hline \multirow{2}{*}{8} & GAL & 3.1 & 1.9 & 1.2 & - \\
\hline & GPS & 9.5 & 6.7 & 2.7 & 0.1 \\
\hline \multirow{2}{*}{9} & GAL & 8.8 & 6.7 & 2.1 & - \\
\hline & GPS & 17.0 & 14.3 & 2.6 & 0.1 \\
\hline \multirow{2}{*}{10} & GAL & 23.2 & 22.4 & 0.8 & - \\
\hline & GPS & 26.1 & 24.2 & 1.9 & - \\
\hline \multirow{2}{*}{11} & GAL & 39.2 & 39.0 & 0.2 & - \\
\hline & GPS & 20.7 & 19.2 & 1.5 & - \\
\hline \multirow{2}{*}{12} & GAL & 21.2 & 21.2 & - & - \\
\hline & GPS & 11.9 & 11.1 & 0.8 & - \\
\hline \multirow{2}{*}{13} & GAL & 3.9 & 3.9 & - & - \\
\hline & GPS & 7.4 & 7.0 & 0.4 & - \\
\hline \multirow{2}{*}{14} & GAL & - & - & - & - \\
\hline & GPS & 1.0 & 1.0 & - & - \\
\hline \multirow{2}{*}{ Total } & GAL & 100 & 95.1 & 4.7 & 0.2 \\
\hline & GPS & 100 & 87.3 & 12.3 & 0.4 \\
\hline
\end{tabular}

Full distribution of VDOP coefficient value (in per cent) and the number of cases without 3D position (in percent) for different angles $\mathrm{H}_{\min }$ for two Galileo constellations, GLONASS constellation and two GPS constellations at latitudes $50-60^{\circ}$ (latitude of Poland) is demonstrated in the table 5. Let us recapitulate that:

- for $\mathrm{H}_{\min } \leq 15^{\mathrm{O}}$ VDOP coefficient is for Galileo system less than 4,

- for $\mathrm{H}_{\min } \geq 10^{\mathrm{O}}$ VDOP coefficient can be for GPS system greater than 20, 
- for $\mathrm{H}_{\text {min }} \geq 20^{\circ}$ the probability of VDOP greater than 20 is for GLONASS system greater than for Galileo and GPS systems considerably.

The distributions of VDOP coefficient value (in percent) for nominal Galileo constellation (27 satellites) and GPS constellation of 27 the youngest satellites for the user at latitude 50$60^{\mathrm{O}}$ for $\mathrm{H}_{\text {min }}=5^{\mathrm{O}}$ if the number of satellites visible by this user is known are shown in the table 6, the same distribution for Galileo constellation $(27+3)$ and GPS constellation of 30 satellites in the table 7 . We can say that for the constellations of 27 satellites VDOP can be less than 2 for the number of visible Galileo and GPS satellites from interval $[7,12]$ and $[5,14]$ respectively, for the constellations of 30 satellites these intervals are equal $[8,13]$ and $[6,14]$.

\section{GPS POSITION AND VERTICAL ACCURACY}

The measurements of GPS position and vertical accuracy (mode "3D") and GPS position (mode "2D") based on stationary receivers were realized in the laboratory of Gdynia Maritime University in Poland. These receivers were: Leica Mk10 Professional, Magnavox MX 200 Professional, MLR FX412 and MAN NR-N124, and real value of these receiver's antenna height is respectively: $27.0 \mathrm{~m}, 27.0 \mathrm{~m}, 24.0 \mathrm{~m}$ and $24.0 \mathrm{~m}$.

In each series selected data, all coordinates of position: in mode $3 \mathrm{D}$ - latitude, longitude and altitude, in mode 2D (for given antenna height) - latitude and longitude, and the number of satellites visible above $\mathrm{H}_{\min }$, were registered by personal computer (PC) with sampling interval of 1 or 2 seconds. If any data was incomplete, this measurement was rejected.

\subsection{Position and vertical accuracy in mode 3D}

The measurements with all four receivers were made in 2005 year and in 2009 year. In each receiver masking elevation angle $\mathrm{H}_{\min }$ was $5^{\circ}$. In each year the measurements were realized in tens series, the period of each series was one hour.

For each series of measurements and for each receiver were calculated: the coordinates of mean position $\mathrm{P}_{\mathrm{m}}$, latitude error $\left(\mathrm{m}_{\varphi}\right)$, longitude error $\left(\mathrm{m}_{\lambda}\right)$, altitude error $\left(\mathrm{m}_{\mathrm{h}}\right)$, horizontal position error $\mathrm{M}$ of $\mathrm{P}_{\mathrm{m}}$ at the $95 \%$ probability level, mean differences between maximum and minimum values of latitude, longitude and altitude, respectively $\Delta \varphi, \Delta \lambda, \Delta \mathrm{H}$, and mean value of altitude $\mathrm{H}$.

For each receiver and for each year the mean values of the differences $\Delta \varphi, \Delta \lambda$ and $\Delta H$, error $\mathrm{M}$, altitude $\mathrm{H}$ and $\mathrm{m}_{\mathrm{h}}$ are presented in the table 8. As before May 2, 2000 in GPS system in SPS C/A-code pseudorange measurements Selective Availability (SA) was the dominant source error, in the determination of vertical component also, the results of the measurements with two receivers (Leica and Magnavox) realized in 1999 year (Januszewski, 2005a) were added in the table 8 for the comparison. We can say that:

- for MX 200 and Mk10 receivers mean value of altitude $\mathrm{H}$ is practical the same before and after May 2, 2000,

- for all four receivers altitude error $m_{h}$ is actually almost the same than horizontal position error $\mathrm{M}$,

- for all receivers the difference between mean value of altitude $\mathrm{H}$ and its real value $\mathrm{H}_{\mathrm{ant}}$ does not exceed 4 metres,

- all differences $\Delta \varphi, \Delta \lambda$ and $\Delta \mathrm{H}$ and the errors $\mathrm{M}$ and $\mathrm{m}_{\mathrm{h}}$ are in 2009 year in almost all cases less than in 2005 , because the pseudorange error factor is less considerably and the number of GPS satellites is actually greater than few years ago, 
- the lowest values of the differences $\Delta \varphi, \Delta \lambda, \Delta \mathrm{H}$ and errors $\mathrm{M}$ and $\mathrm{m}_{\mathrm{h}}$ are for MAN receiver in each year.

Table 8. GPS System, position "3D"; mean differences between maximum and minimum values of latitude, longitude and altitude, respectively $\Delta \varphi, \Delta \lambda, \Delta \mathrm{H}[\mathrm{m}]$, horizontal position error $\mathrm{M}$ at the $95 \%$ probability level [m], mean value of altitude $\mathrm{H}$, altitude error $m_{h}(95 \%)[\mathrm{m}]$

\begin{tabular}{|c|c|c|c|c|c|c|c|c|}
\hline Receiver & Year & $\begin{array}{c}\mathbf{H}_{\text {ant }}[\mathbf{m}] \\
\text { (real } \\
\text { value) }\end{array}$ & $\Delta \varphi$ & $\Delta \lambda$ & $\Delta \mathbf{H}$ & $\mathbf{M}$ & $\mathbf{H}$ & $\mathbf{m}_{\mathbf{h}}$ \\
\hline \multirow{3}{*}{ Mk10 } & 1999 & \multirow{3}{*}{27.0} & 118.5 & 108.5 & 206.8 & 70.3 & 30.5 & 90.0 \\
\hline & 2005 & & 24.5 & 10.9 & 47.7 & 7.2 & 24.5 & 9.8 \\
\hline & 2009 & & 7.2 & 7.3 & 10.6 & 3.2 & 22.6 & 4.2 \\
\hline \multirow{3}{*}{ MX200 } & 1999 & \multirow{3}{*}{27.0} & 90.7 & 103.5 & 155.1 & 58.8 & 27.3 & 72.2 \\
\hline & 2005 & & 14.3 & 10.0 & 24.0 & 4.4 & 26.1 & 6.2 \\
\hline & 2009 & & 4.3 & 4.2 & 6.9 & 2.6 & 27.2 & 3.0 \\
\hline \multirow{2}{*}{ MLR } & 2005 & \multirow{2}{*}{24.0} & 18.5 & 10.6 & 32.0 & 25.0 & 20.1 & 6.4 \\
\hline & 2009 & & 18.9 & 7.7 & 28.0 & 6.1 & 20.2 & 9.0 \\
\hline \multirow{2}{*}{ MAN } & 2005 & \multirow{2}{*}{24.0} & 5.2 & 3.7 & 7.2 & 1.2 & 23.9 & 3.0 \\
\hline & 2009 & & 1.6 & 2.0 & 3.0 & 1.1 & 20.2 & 1.2 \\
\hline
\end{tabular}

\subsection{Position accuracy in mode $2 \mathrm{D}$ for different receiver's antenna heights}

The measurements in mode 2D based on the receivers MX200 and Mk10 were made in 2005 and 2009 for 5 different antenna heights $(0,50,100,200,500 \mathrm{~m})$ and additionally for real value of the receiver's antenna height $\mathrm{H}_{\text {ant }}=27.0 \mathrm{~m}$ for both receivers. The measurements based on MLR receiver realized in 1999 for the same 5 antenna heights and for real value $\mathrm{H}_{\text {ant }}$ $=24.0 \mathrm{~m}$ (Januszewski, 2005a) were taken into account also.

For each series of measurements and for each receiver were calculated: the coordinates of mean position $\mathrm{P}_{\mathrm{m}}$, latitude error $\left(\mathrm{m}_{\varphi}\right)$, longitude error $\left(\mathrm{m}_{\lambda}\right)$, horizontal position error $\mathrm{M}$ of $\mathrm{P}_{\mathrm{m}}$ at the $95 \%$ probability level, mean differences between maximum and minimum values of latitude and longitude, respectively $\Delta \varphi, \Delta \lambda$.

For all these three receivers, for each year and for each $\mathrm{H}_{\mathrm{ant}}$ the mean values of the differences $\Delta \varphi, \Delta \lambda$ and error $\mathrm{M}$ are presented in the table 9. We can recapitulate that:

- the lowest values of the differences $\Delta \varphi, \Delta \lambda$ and the error $M$ are for real values of $H_{\text {ant }}$ for all receivers,

- the differences $\Delta \varphi, \Delta \lambda$ and the error $\mathrm{M}$ increase with the difference between $\mathrm{H}_{\text {ant }}$ and its real value for all receivers,

- for each receiver and for each $\mathrm{H}_{\text {ant }}$ the differences $\Delta \varphi$ and $\Delta \lambda$ (in degrees) are practically the same, but as $\Delta \lambda$ depends on latitude, its value in meters is less. 
Table 9. GPS System, MX200, MLR and Mk10 receivers, position "2D”; mean differences between maximum and minimum values of latitude and longitude, respectively $\Delta \varphi$ and $\Delta \lambda$

$[\mathrm{m}]$, horizontal position error $\mathrm{M}$ at the $95 \%$ probability level $[\mathrm{m}]$ for different receiver's antenna height $\mathrm{H}_{\mathrm{ant}}$ and for different years of measurements in Gdynia

\begin{tabular}{|c|c|c|c|c|c|c|c|c|c|c|}
\hline \multirow{2}{*}{$\begin{array}{c}\mathbf{H}_{\text {ant }} \\
{[\mathbf{~ m ~ ] ~}}\end{array}$} & \multirow{2}{*}{ Year } & \multicolumn{3}{|c|}{ MX 200} & \multicolumn{3}{|c|}{ MLR } & \multicolumn{3}{|c|}{ Mk 10} \\
\hline & & $\Delta \varphi$ & $\Delta \lambda$ & $\mathbf{M}$ & $\Delta \varphi$ & $\Delta \lambda$ & $\mathbf{M}$ & $\Delta \varphi$ & $\Delta \lambda$ & $\mathbf{M}$ \\
\hline \multirow{3}{*}{0} & 1999 & 82.0 & 104.1 & 58.5 & - & - & - & 123.1 & 106.7 & 74.2 \\
\hline & 2005 & 19.5 & 16.8 & 9.6 & 18.5 & 10.6 & 20.0 & 33.5 & 20.8 & 11.8 \\
\hline & 2009 & 11.1 & 6.2 & 6.1 & 10.4 & 6.3 & 6.1 & 42.4 & 18.7 & 11.3 \\
\hline \multirow{2}{*}{27} & 2005 & 14.4 & 10.5 & 3.8 & 18.5 & 10.5 & 19.6 & 9.9 & 11.1 & 4.8 \\
\hline & 2009 & 6.3 & 3.9 & 2.9 & 8.5 & 5.8 & 3.6 & 9.6 & 7.3 & 3.9 \\
\hline \multirow{3}{*}{50} & 1999 & 95.5 & 76.2 & 54.6 & - & - & - & 129.7 & 997.7 & 75.1 \\
\hline & 2005 & 36.5 & 22.8 & 12.4 & 18.6 & 10.7 & 18.6 & 34.5 & 18.6 & 11.8 \\
\hline & 2009 & 13.9 & 2.8 & 9.0 & 12.6 & 7.5 & 7.9 & 60.7 & 58.3 & 22.6 \\
\hline \multirow{3}{*}{100} & 1999 & 98.7 & 110.0 & 64.7 & - & - & - & 105.3 & 107.5 & 70.5 \\
\hline & 2005 & 103.0 & 58.4 & 32.6 & 92.6 & 53.1 & 34.8 & 94.3 & 58.0 & 31.4 \\
\hline & 2009 & 32.6 & 20.0 & 25.0 & 45.6 & 16.0 & 32.0 & 66.2 & 40.0 & 32.5 \\
\hline \multirow{3}{*}{200} & 1999 & 121.7 & 127.7 & 79.8 & - & - & - & 131.1 & 125.0 & 84.7 \\
\hline & 2005 & 229.5 & 135.4 & 73.6 & 203.7 & 127.4 & 75.2 & 192.2 & 106.9 & 84.2 \\
\hline & 2009 & 91.1 & 57.9 & 72.4 & 64.6 & 61.3 & 65.8 & 129.9 & 134.3 & 64.2 \\
\hline \multirow{3}{*}{500} & 1999 & 244.7 & 295.7 & 170.8 & - & - & - & 180.9 & 148.6 & 108.0 \\
\hline & 2005 & 615.0 & 403.0 & 349.2 & 481.5 & 339.9 & 239.2 & 554.8 & 288.6 & 242.8 \\
\hline & 2009 & 155.9 & 171.0 & 130.2 & 237.4 & 85.5 & 175.0 & 484.6 & 261.3 & 263.6 \\
\hline
\end{tabular}

\section{THE USE OF VERTICAL COMPONENT OF SNS IN MARITIME NAVIGATION}

Nowadays each sea-going vessel has on the bridge at least one GPS receiver. The measurements realized in GPS receiver, of vertical component in particular, can provide the determining the ellipsoidal heights for overhead structures to avoid striking, and additionally with acoustic soundings highly accurate ellipsoidal depths of the floor to avoid the grounding. The last possibility is very useful in new areas or by filling gaps independent of the stage of the tide and any tidal datum.

As vertical position accuracy was greater than horizontal position accuracy, the sea user was not interested in the positioning in mode 3D. Since the number of GPS satellites increased to 30, even 31, VDOP coefficient value decreased and pseudorange error is less than before considerably, vertical position accuracy can be few meters. That's why nowadays the GPS vertical component can be taken into account by the sea user to determine the clearances.

All measurements realized in GPS receivers are referenced to the WGS-84 datum. As the ellipsoid (E) of this datum can be below or above the sea surface (S), the surveyed ellipsoidal depths or heights can be plus or minus. In both cases the location of sea floor $(\mathrm{F})$, keel $(\mathrm{K})$, the height of the installation of the receiver's antenna $(\mathrm{G})$ and the highest mast $(\mathrm{H})$ must be taken in to account (fig.1). The magnitude of geoid height (the height of given point above the 
ellipsoid) can be several tens of meters, the height of the GPS antenna above keel of some vessels 40 meters or sometimes even more, the height of overhead structure $(\mathrm{O})$ above sea surface can be several tens of meters and the draught more than 10 meters.

The distances HG, HK and GK are constant and well known. As the surface (S) changes her own height and the draught depends on the loading the distances essential for sea user, the distances $\mathrm{KF}, \mathrm{SF}, \mathrm{GF}, \mathrm{HF}$ and $\mathrm{OH}$ in particular change also. As additionally the vertical component obtained from GPS receiver is calculated in WGS-84 datum, we must distinct seven different possible location of the ellipsoid WGS-84:

- below the sea floor $(\mathrm{F})$,

- between the sea floor $(\mathrm{F})$ and $\operatorname{keel}(\mathrm{K})$,

- between the keel $(\mathrm{K})$ and the sea surface $(\mathrm{S})$,

- between the sea surface (S) and GPS antenna (G),

- between GPS antenna $(\mathrm{G})$ and the highest mast $(\mathrm{H})$. On some ships GPS antenna can be installed on the highest mast, therefore the distance GH is equal zero,

- between highest mast $(\mathrm{H})$ and overhead structure $(\mathrm{O})$,

- above the overhead structure (O).

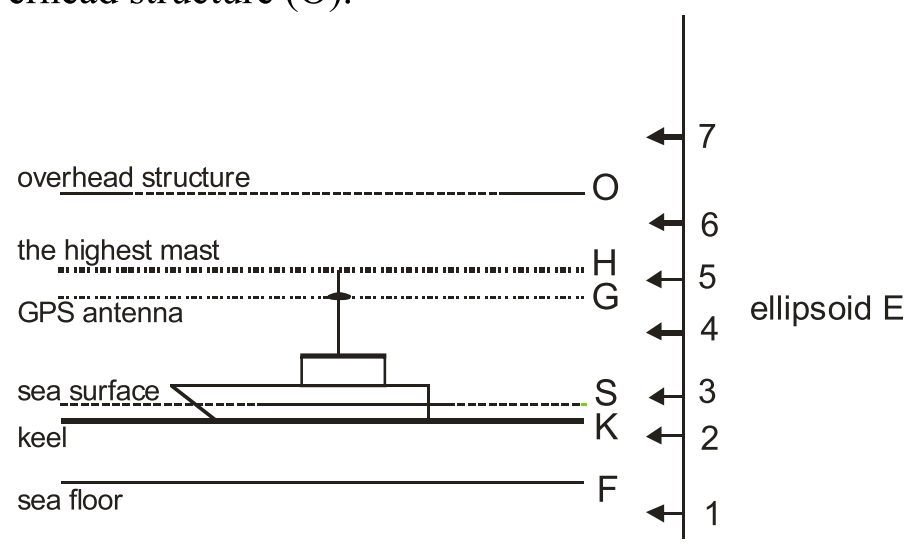

Fig. 1. The possible location of the ellipsoid $\mathrm{E}$ in maritime navigation

Obtained from the detailed measurements the ellipsoidal depth of sea floor (FE) and the height (above ellipsoid) of the overhead structure (OE) can be stored in the Marine Information System - MIS (Kumer M. 2005). The knowledge of these two parameters permit the deck officer the calculations of the clearance for ship's keel (KF) and the clearance for the ship's highest mast $(\mathrm{OH})$.

In the case of ellipsoid below sea floor the clearance KF can be calculated from the relation:

$$
\mathrm{KF}=\mathrm{KE}-\mathrm{FE}=(\mathrm{GE}-\mathrm{GK})-\mathrm{FE}
$$

where:

GE - ellipsoidal height of GPS antenna, obtained from the GPS receiver (vertical component),

GK - the height of GPS antenna above the keel, known from the ship's papers,

$\mathrm{FE}$ - the height taken from the database.

The clearance $\mathrm{OH}$ can be calculated from the relation:

$$
\mathrm{OH}=\mathrm{OE}-\mathrm{HE}=\mathrm{OE}-(\mathrm{HG}+\mathrm{GE})
$$

where: 
$\mathrm{OE}$ - the height taken from the database,

$\mathrm{HG}$ - the distance between the highest mast and GPS antenna, known form the ship's papers,

$\mathrm{GE}-$ as in the relation (1).

\section{CONCLUSIONS}

- there is not a direct relation between a number ls of satellites visible above $H_{\text {min }}$ and VDOP coefficient value, but we can realize "when ls is greater, VDOP is less" and vice versa "when ls is less, VDOP is greater".

- VDOP coefficient value is for Galileo system less than for GPS system in open areas at middle latitudes, in restricted areas at all latitudes,

- at latitude $0-70^{\circ}$ the increase of the number of satellites is for the user of vertical component more favourable in the case of GPS system than in the case of Galileo,

- at high latitudes GLONASS constellation of 24 satellites can provide greater vertical accuracy than Galileo constellation or GPS constellation of 30 satellites,

- Satellite Navigation Systems can provide the accuracy necessary for determining ellipsoidal depths and ship operations as the keel and overhead obstruction clearance,

- the altitude error of the position fixed in the given time in mode "3D"depends on the receiver

- if the user's position is fixed in mode "2D" the receiver's antenna height must be known with high accuracy, if not, horizontal accuracy decreases considerably.

\section{REFERENCES}

GPS Health in Question (2009). GPS World, vol.20, No.6, 8

Hofmann-Wellenhof B. et al. (2008) GNSS Global Navigation Satellite Systems GPS, GLONASS, Galileo \& more, Springer, Wien NewYork

Januszewski J. (2005a) GPS Vertical Accuracy for Different Constellations, str.181-190, Zeszyty Naukowe nr 6(78), Akademia Morska w Szczecinie, Szczecin

Januszewski J. (2005b) Vertical Accuracy in Satellite Navigation Systems, European Navigation Conference Global Navigation Satellite Systems, Munchen

Kaplan E.D., Hegarty C.J. (2006) Understanding GPS Principles and Applications, Artech House, Boston/London

Kumer M., Maul G.A. (2005). Time-Invariant Sea-Floor Depths Using the Ellipsoid As ZeroReference Surface, GPS World, No.9, 16-21

Roper E. (2010) GPS Status and Modernization, Munich Satellite Navigation Summit, Munich

$\underline{\text { www.glonass-ianc.rsa.ru }}$

www.navcen.uscg.gov

Received: 2010-10-01,

Reviewed: 2010-12-13, by Z. Rzepecka,

Accepted: 2010-12-14. 